\title{
Glossary
}

\section{Glossary: causality in public health science}

\author{
M Susser
}

Association is one of three properties of cause described by Hume. ${ }^{1}$ (See Properties). Association of any presumed cause with its presumed effect is judged statistically by the presence and strength of probabilities based on preset expectations of variation (so called chance occurrence). In epidemiology, other criteria such as consistency upon replication are also important. With the exception of antagonistic causes acting simultaneously, as in feed back systems, absence of association refutes causality.

Causal inference is the thought process that tests whether a relation of cause to effect exists. An extensive philosophical literature considers the questions involved, ${ }^{1-8}$ as does a more recent epidemiological literature. ${ }^{9-22}$

Causality describes the property of being causal, the presence of cause, or ideas about the nature of the relations of cause and effect.

Causation means either the production of an effect, or else the relation of cause to effect.

Causes produce or occasion an effect. Some philosophers, and epidemiologists drawing largely on experimental sciences, require that causes be limited to well specified and active agents producing change. As by definition public health sciences entail an obligation to population health, among causes they must needs include contextual factors such as the more or less steady state conditions of sex or social position or climate or location, which can seldom be structured experimentally to produce change.

Confounding occurs where an apparent association between a presumed causal variable and an outcome is in fact accounted for by a third variable, or "common cause" not in the postulated causal pathway; such a variable must be itself associated with both presumed cause and outcome.

Connection is one of three essential properties of cause specified by Hume ${ }^{1}$ and, being the most difficult to establish, is also the most crucial (see Direction, a synonym, for definition).

Counterfactual logic ${ }^{19}$ limits causes to change agents (thus excluding steady state conditions) and demands formulations of causal relations amenable to mathematical logic. An entity, after exposure to the change agent, is compared in a thought experiment with the same entity had there been no exposure. Unattainable in practice, instead the outcome is adjusted statistically, preferably in terms of Bayesian probability theory.
Criteria for causation (or guidelines, or canons as in J S Mill, ${ }^{2}$ or postulates as in Henle ${ }^{20}$ and $\mathrm{Koch}^{9}$ ) assist judgment. ${ }^{13}{ }^{14}{ }^{21}$ At the least, they can be grouped under at least five categories (with subcategories for several): these are strength; specificity (in the cause; and in the effect); consistency (replicability; survivability); predictive performance; and coherence or plausibility (theoretical; factual; biological; statistical). ${ }^{22}$ Each is useful depending on the property under test and the type and quality of available research evidence. Some epidemiologists deny their usefulness. ${ }^{15}$

Deductive logic predicts particular outcomes from prior general hypotheses-that is, it proceeds from the general to the particular. This important mode of scientific procedure for arriving at a judgment of causation is the only one admitted as legitimate in logic by Popper and his followers in epidemiology. ${ }^{15} \mathrm{In}$ scientific practice, insistence on this logic alone has never proved sustainable.

Determinants are entities that can be simply defined as single specified causes - that is, something making a difference to outcome. ${ }^{14}$ Bunge $^{4}$ provides and discusses at length a highly refined classification.

Direction, a term used by Blalock, ${ }^{23}$ is synonymous with Hume's causal property of "connection". It can be defined as the presence of a change in state (the effect) consequent on change in independent antecedent states (the cause). For epidemiological purposes, it is a critical and ultimately defining property. In practice, its demonstration depends on establishing an array of causal criteria with all potential alternative explanations and possible confounding accounted for.

Germ theory postulates proximate, singular microbial causes of disease. In the last two decades of the 19th century the thought and work of Henle, ${ }^{20}$ Koch $^{9}$ and others displaced the Miasma theory (see Miasma). For some 75 years thereafter, germ theory dominated an Anglophone laboratory-based epidemiology and focused on infectious disease control. ${ }^{16}{ }^{24}$

Henle-Koch postulates (of which there were four) provided criteria for judgements about the presence of micro-organisms as causes of disease that were widely adopted as formulated by Koch in 1882 and are still occasionally cited. Restated in summary, ${ }^{21}$ they require complete specificity in a unique and unconfounded bacterial cause (postulates 1 and 2), 
which must be rigorously tested by both the criterion of biological coherence (postulate 3) and predictive performance on experimental laboratory test. Insistence on the invariable presence of the organism (postulate 1) conforms with the original notion of necessary and sufficient cause. German medical scientists soon saw that the postulates do not allow for the operation of multiple causes-nor indeed do they cater for causal relations not susceptible to experimentation. They established a 20 th century consensus about multifactorial causality, ${ }^{17}$ an idea that did not penetrate Anglophone epidemiology until mid-century.

Hume ${ }^{1}$ defined three properties essential to any cause (see Properties), but created an enduring problem for causal inference when he argued that one could not demonstrate any "necessary connection" from cause to effect. For instance he could find no logical compulsion (read by Russell, Popper and others to mean by induction) to believe the sun would always rise on the morrow. Despite Hume and his followers, ${ }^{1515}$ all scientists are obliged to practice induction (see Induction) for verifying their ideas.

Hypothetico-deductive method is a formulation of deductive logic that, demarcating the limits of science as that which is testable, requires a testing procedure to formulate hypotheses a priori, and aims only to reject the hypothesis. As attributed to Popper and accepted by his followers, ${ }^{515}$ the underlying philosophical assumption is that a hypothesis can never be proved or verified but, at best, only corroborated. The proper rejection by most scientists of the assumption of nonverifiability does not preclude the application of what is a useful testing procedure.

Inductive logic seeks to generalise by reasoning from assembled particular observations (see Verification). Its first proponent as applied to science was Francis Bacon, ${ }^{25}$ and it has been an important mode of scientific reasoning ever since.

Koch's postulates (see Henle-Koch postulates).

Miasma theory (redolent of the "Airs, Waters and Places" of the Hippocratic writers) posited the major cause of disease as foul emanations from soil, water and air. As promulgated by Thomas Sydenham in the 17th century, it became the dominant theory in public health through the first three quarters of the 19th century.

Multiple cause theory ${ }^{10121426}$ recognises a need to accommodate multiple coexisting causes for single diseases or other health disorders. The theory, achieved consensus late (see Henle-Koch postulates) but dominated Anglophone epidemiology through the second half of the 20th century, when the study of chronic non-infectious disease became the leading public health concern of that era.

Necessary and sufficient causes, as Galileo defined cause in the 17th century for the experimental sciences he advocated, came to mean one to one relations of specific causes to given effects. A breakdown of the two terms taken separately produces four categories, which together admit of multiple causes, ${ }^{14}$ as follows: necessary and sufficient (both qualities are always present); necessary but not sufficient (always present but only together with others); sufficient but not necessary (sometimes effective alone); or, probably most commomly, neither necessary nor sufficient but contributory (sometimes present but always with other causes). ${ }^{14}$ (See Public health sciences).

Paradigms, in the sense used by Kuhn, ${ }^{7}$ are concepts of cause that dominate a given science in a given period. Defined by a number of criteria, a particular paradigm reflects causal concepts operative in "normal science" that (in Kuhn's but not everyone's view) can only be displaced by scientific revolutions. Whether miasma, germs, or multiple risk factors, each causal theory of disease reflects a different paradigm that largely governed the thought of successive eras of the past two centuries. ${ }^{27} 28$

Popper followed Hume in rejecting induction. Instead, he insisted strictly on deduction, allowing the sole capability of science to be the falsification of prior hypotheses (see Hypothetico-deductive method), rejecting any place for verification (see Hume; see also Verification). ${ }^{15}$

Properties of cause (as described by Hume in $1739^{1}$ ) are association (cause and effect occur together), time order (causes precede effects), and "connection" or direction - that is, repeatedly demonstrable, hence predictable, linkages existing between cause and effect. Although Hume denied that such prediction was possible, in other essentials, his analysis endures and has hardly been improved on.

Public health sciences, predominantly observational, is by definition committed to the health of populations. Ultimately, its many components must accommodate multiple causes acting in the dimensions of time, space and structure, and thus at several relevant levels of organisation (from molecules to the encompassing environment). ${ }^{28}$

Risk factors are synonymous with the determinants of the multiple cause era of the latter half of the 20th century (see Determinants, also Paradigms, also Multiple causes). Thus over the past half century, their hoped for discovery has motivated the search for causes of chronic disease at the individual level of organisation.

Sufficient and component cause ${ }^{29}$ is an idea propounded for the interpretation of multiple risk factors operating sufficiently and jointly to form one or more component causes (in different combinations), each of which is capable of producing or contributing to a given effect (see Risk factors). The frequency of the components within a sufficient cause influences their relative strength. The focus of this heuristic model, however, bypasses issues of antecedents, causal sequence and process.

Time-order, as a property of cause, relies on tests and designs that secure the sequence of cause before effect; reversal assures elimination of a putative cause.

Verification is the process by which scientists ultimately convert hypotheses from speculative ideas to basic facts. It usually involves both the 
rejection of false hypotheses by deduction (see Deductive logic) and, finally, the undisputed acceptance of hypotheses by induction and consensus (see Inductive logic), as for example, with the universal recognition, as undeniable fact, of William Harvey's hypothesis of the circulation of the blood. In its broadest sense it is the process of causal inference.

Web of causation is a metaphor ${ }^{12}$ for a theory of sequential multiple causes. Originally deployed mainly for an epidemiology practised at the individual level of organisation, but not necessarily confined to it, the metaphor can be and has been extended to incorporate a sequence of multiple dimensions. ${ }^{30}$

1 Hume D. A treatise of human nature. 1739. Book 1. Of the understanding. Section 2. Reprinted by La Salle, IL: Open Court Publishing Company, 1945.

2 Mill JS. A system of logic: ratiocinative and inductive. 1856. Republished London: George Routledge, 1892.

3 Russell B. The problems of philosophy. Oxford: Oxford University Press, 1912.

4 Bunge M. Causality in modern science. 3rd ed. New York: Dover Publications, 1979.

5 Popper KR. The logic of scientific discovery. Revised ed. New York: Harper and Row, 1968. [First published as Logik der York: Harper and Row, 1968. [First pub

6 Fleck L. Genesis and development of a scientific fact (1935). Translated by Bradley F, Trenn TJ. Trenn TJ, Merton RK, eds. Chicago, IL: University of Chicago Press, 1979.

7 Kuhn TS. The structure of scientific revolutions. Chicago: Chicago University Press, 1970.

8 Latakos I. Falsification and the methodology of scientific research programs. In: Latakos I, Musgrave A, eds. Criticism and the growth of knowledge. New York: Cambridge University Press, 1970.

9 Koch R. Die aetiologie der Tuberkulose. 1882. Republished in Schwalbe J, ed. Gesammelte Werke von Koch. Leipzig: Georg Thieme Verlag 1912:428-55.

10 Hammond EC. Cause and effect. In: Wynder ES, ed. The biologic effects of tobacco. Boston: Little, Brown, 1955:17196.
11 Yerushalmy J, Palmer CE. On the methodology of investigations of etiologic factors in chronic diseases. $\mathcal{F}$ Chronic Dis 1959;10:27-40.

12 MacMahon B, Pugh T, Ipsen J. Principles of epidemiology. Boston: Little, Brown, 1960:18-21.

13 Hill AB. Environment and disease: Association or causation? Proc R Soc Med 1965;58:295-300.

14 Susser M. Causal thinking in the health sciences. New York: Oxford University Press, 1973.

15 Rothman KJ, ed. Causal inference. Chestnut Hill, MA: Epidemiology Resources, 1988.

16 Evans AS. Causation and disease: a chronological journey. New York: Plenum, 1993.

17 Von Engelhardt D. Causality and conditionality in medicine around 1900. In: Delkeskamp-Hayes C, Cutter MAG, eds. Science, technology, and the art of medicine. Dordrecht: Kluwer Academic, 1993:75-104.

18 Rothman KJ, Greenland S, eds. Modern epidemiology. 2nd edition. Boston: Little, Brown, 1998.

19 Pearl J. Causality. New York: Cambridge University Press, 2000

20 Henle J. On Miasmata and Contagia (1840). Translated by George Rosen. Baltimore: The Johns Hopkins Press, 1938

21 United States Department of Health, Education and Welfare. Smoking and health. Report of the Advisory Committee to the Surgeon-General. Washington, DC: Public Health Service, 1964.

22 Susser $M$. What is a cause and how do we know one? A grammar for pragmatic epidemiology. Am 7 Epidemiol 1991;33:635-48.

23 Blalock HM. Causal inference in non-experimental research. Chapel Hill, NC: University of North Carolina Press, 1964

24 Winslow C-E A. The life of Hermann M Biggs. Philadelphia: Lea and Febiger, 1929.

25 Bacon F. The new organon and related writings (1599). Reprinted. In: Anderson FH, ed. New York: Bobbs-Merril, 1960.

26 Fisher RA. Indeterminism and natural selection. Philos Sci 1934:1:99-117.

27 Susser M. Evolution of epidemiology in the United States after world war II: the evolution of technique. Epidemiol Rev 1985;7:147-77.

28 Susser M, Susser E. Choosing a future for epidemiology I. Eras and paradigms. Am F Public Health 1996;86:668-73.

29 Rothman KJ. Modern epidemiology. Boston: Little, Brown, 1986.

30 Krieger N. Epidemiology and the web of causation: has anyone seen the spider? Soc Sci Med 1994;39:887-903. 